\title{
THE PROBLEMS OF MEDIATION PROCEDURE IN CIVIL PROCEEDINGS
}

\author{
Olga A. Derbisheva \\ Donetsk Academy of Internal Affairs of the Ministry of Internal Affairs of the Donetsk People's Republic, \\ Donetsk, Donetsk People's Republic
}

Introduction: the paper discusses the actual problems of the legislation of the mediation procedure, as well as the existing obstacles to the development of civil practice in the application and improvement of the alternative dispute resolution procedure. The purpose of the paper is to study the problems of the institution of the mediation procedure, to understand the concept of conciliation procedures for further improving and forming recommendations for the efficiency of justice. In the process of consideration, the doctrinal problems, the formal-legal approach and the formallegal, systematic methods were used. Results: the study of the legislation allows us to identify the provisions that need to be improved and changed for a more active and complete implementation of the mediation procedure in public relations. Conclusions: the author identifies the ways to resolve such difficulties at the pre-trial stage to optimize the judicial burden. The dispute resolution procedure with the participation of a mediator is considered from the position of an effective alternative to judicial proceedings. It has a legislative consolidation, but there are a number of regulatory gaps that require solving a large number of tasks to improve them. It is necessary to carry out the extensive work in order to integrate this procedure into the civil and arbitration process: to develop a strategy for the systematic development of the mediation institute, to inform the public, the business community and practicing lawyers in order to introduce the procedure and develop the practice of application, and also, to solve the problem with the professional training of mediators and to encourage them to engage in this type of activity on a professional basis.

Key words: mediation, mediator, dispute resolution, dispute, legislation.

Citation. Derbisheva O.A. The Problems of Mediation Procedure in Civil Proceedings. Legal Concept $=$ Pravovaya paradigma, 2021, vol. 20, no. 1, pp. 118-123. (in Russian). DOI: https://doi.org/10.15688/lc.jvolsu.2021.1.18

УДК 347.93

ББК 67.4
Дата поступления статьи: 28.12.2020

Дата принятия статьи: 25.01.2021

\section{ПРОБЛЕМЫ ПРОЦЕДУРЫ МЕДИАЦИИ В ГРАЖДАНСКОМ СУДОПРОИЗВОДСТВЕ}

\section{Ольга Александровна Дербишева}

Донецкая академия внутренних дел Министерства внутренних дел Донецкой Народной Республики, г. Донецк, Донецкая Народная Республика

Введение: в статье рассматриваются актуальные проблемы законодательства процедуры медиации, а также существующие препятствия к развитию цивилистической практики применения и совершенствования 
альтернативной процедуры урегулирования споров. Целью настоящей статьи является исследование проблем института процедуры медиации, понимание концепции примирительных процедур для дальнейшего повышения и формирования рекомендаций оперативности правосудия. В процессе рассмотрения используется доктринальная проблематика, формально-юридический подход и метод формально-юридический, системный. Результаты: исследование законодательства позволяет выявить положения, которые требуют доработки и изменения для более активного и полного внедрения процедуры медиации в общественные отношения. Выводы: выявляются способы разрешения такого рода трудностей на досудебном этапе по оптимизации судебной нагрузки. Процедура решения споров с участием посредника рассматривается с позиции эффективной альтернативы судебному разбирательству. Имеет законодательное закрепление, однако существует ряд пробелов нормативного регулирования, которые требуют решения большого количества задач по их совершенствованию. Необходимо провести объемную работу для того, чтобы интегрировать данную процедуру в гражданский и арбитражный процесс. Разработать стратегию планомерного развития института медиации, проводить информирование населения, бизнес сообщества и практикующих юристов с целью внедрения процедуры и наработки практики применения. Также решить задачу с профессиональной подготовкой медиаторов и стимулирования занятия данным видом деятельности именно на профессиональной основе.

Ключевые слова: медиация, посредник, разрешение споров, спор, законодательство.

Цитирование. Дербишева О. А. Проблемы процедуры медиации в гражданском судопроизводстве// Legal Concept $=$ Правовая парадигма. - 2021. - T. 20, № 1. - C. 118-123. - DOI: https://doi.org/10.15688/lc.jvolsu.2021.1.18

\section{Введение}

Исследование процедуры досудебного урегулирования спора обусловлено принятием в 2011 г. Федерального закона «Об альтернативной процедуре урегулирования споров с участием посредника», а также внесением изменений в ряд других нормативных правовых актов, что позволяет по прошествии достаточно долгого времени выделить основные проблемы, препятствующие развитию института медиации в доктрине и практике.

Исследованием проблемы процедуры медиации занимались такие ученые, как И.В. Решетникова, О.В. Аллахвердова, Е.Н. Иванова, О.В. Исаенкова, А.Д. Карпенко и другие.

\section{Становление института медиации}

Решение споров с участием посредников существовало с древних времен, однако как правовой институт медиация зародилась в США. Появление такого способа решения проблем в американской системе было обусловлено неспособностью судов обеспечить полное, качественное и быстрое разрешение споров в связи с большим количеством обращений. Решением явилось предложение использовать одно из министерств в качестве нейтрального посредника [1]. Когда стало ясно, что подобный формат решения споров имеет успех, был принят специальный феде- ральный закон, который закреплял возможность разрешения спора во внесудебном порядке.

Если в США и Европе процедура медиации начала развиваться в прошлом столетии и на данный момент уже принята обществом, то в России медиация появилась только в 2011 году. В связи с этим существует большое количество проблем в применении посредничества при решении споров и существенное количество пробелов в законодательстве. Медиация в Российской Федерации (далее - РФ) осуществляется на основании Федерального Закона от 27.07.2010 № 193-Ф3 «Об альтернативной процедуре урегулирования споров с участием посредника (процедура медиации)» (далее - Закон о медиации).

\section{Современное состояние процедуры медиации}

Несмотря на такие преимущества медиации, как конфиденциальность, неформальность и скорость проведения, отсутствие состязательности и максимальное создание условий для совместного поиска решения сложившихся разногласий, до сих пор остается ряд неустраненных проблем и пробелов в законодательстве.

В Законе «О медиации», а именно в ч. 2 ст. 1 указано, что процедура медиации мо- 
жет быть применена к спорам, возникшим из гражданских, административных, трудовых и семейных, а также отношений, связанных с осуществлением предпринимательской и экономической деятельности. При такой формулировке исключаются земельные и жилищные правоотношения. Также возникает вопрос по поводу применения медиации при решении споров между предпринимателями, поскольку ч. 5 ст. 1 Закона «О медиации» указывает, что данная процедура не может применяться в случае, если такие споры могут затронуть права и законные интересы третьих лиц, не участвующих в процедуре медиации, публичные интересы [10]. Это означает, что в последствии медиативное соглашение может быть признано недействительным при несоблюдении условий, указанных в статье, однако в Законе «О медиации» не говорится о том, как именно стоит определять данных лиц. Исходя из того, что соглашение, принятое с помощью медиации в последующем может быть оспорено лицом, которое не было привлечено к разрешению спора, данная процедура становится менее привлекательной для использования предпринимателями.

Вышеназванный Федеральный закон определяет, что деятельность медиатора может осуществляться как на профессиональной основе, так и на непрофессиональной. Такое разделение другими авторами воспринимается оправданно. Большее количество вопросов возникает относительно того, что Закон совершенно не определяет, каким образованием должен владеть медиатор, который осуществляет данный вид деятельность не профессионально и должен ли он иметь образование вовсе. В то же время ст. 16 Закона «О медиации» определяется, что профессиональный медиатор должен иметь высшее образование и получить дополнительное профессиональное образование по вопросам применения процедуры медиации.

\section{Усовершенствование}

\section{примирительного урегулирования споров}

На наш взгляд, данный пробел стоит устранить путем внесения изменений в закон, а именно положения ч. 2 ст. 15 и ч. 1 ст. 16 Закона «О медиации» дополнить обязательным обладанием у лица высшего юридического образования. Наличие у посредника юридического образования позволит более профессионально оценивать сложившуюся между сторонами ситуацию и помогать гражданам и предпринимателям находить правильное направление в решении их проблем так, чтобы права одной и другой стороны не были нарушены. В связи с разделением медиаторов на профессиональных и непрофессиональных стоит законодательно закрепить, какие споры должны находится в исключительном ведении профессиональных медиаторов, а какие могут быть рассмотрены непрофессиональными. Закрепление “подведомственности” медиаторов важно тем, что непрофессиональный посредник в некоторых случаях может навредить мирному урегулированию спора между сторонами.

Также стоит добавить, что не в полной мере прописана ответственность медиаторов. В соответствии с Законом, медиатор может нести ответственность в порядке, установленном гражданским законодательством. В то же время статья 5 и 6 Закона о медиации гласит, что вся информация, относящаяся к процедуре медиации, сохраняется конфиденциальной, если это не установлено Законом или стороны договорились об ином, также п. 1.1 ч. 3 ст. 51 Кодекса административного судопроизводства РФ (далее - КАС РФ) [5], п. 1 ч. 3 ст. 69 Гражданского процессуального кодекca РФ (далее - ГПК РФ) [2] устанавливает невозможность допроса медиатора в качестве свидетеля при разрешении дела.

Из вышесказанного следует, что при нарушении принципа конфиденциальности стороны могут обратиться в суд для восстановления своих прав, однако для медиатора в его непосредственной деятельности никаких последствий не будет. В связи с этим, на наш взгляд, следует дополнить законодательство об административных правонарушениях специальной нормой, предусматривающей ответственность за нарушение конфиденциальности в виде штрафа, а в случаях неоднократного нарушения - запрета на осуществление деятельности посредника.

Экономический барьер к использованию процедуры медиации обусловлен высокой стоимостью услуг профессиональных медиато- 
ров. В качестве примера, услуги одной из организаций обеспечивающих проведение медиации при условии, что конфликт носит частный характер и сумма претензий не превышает 50 тыс. руб. регистрационный взнос при подаче заявления составит 3200 руб., сама процедура медиации, а точнее один час процедуры - 3200 руб., стоимость подготовки медиативного соглашения - 4500 рублей. Таким образом, получается, стоимость процедуры медиации равна 10900 руб., а, если материальных претензий в конфликте нет, стоимость процедуры медиации обойдется в 9800 рублей [6]. Это с учетом того, что к процедуре не привлекались специалисты или эксперты, услуги которых оплачиваются дополнительно. При обращении к профессиональным медиаторам до судебного разбирательства стоимость выглядит не так устрашающе, но в случае обращения к медиации в процессе судебного разбирательства, то есть после уплаты государственной пошлины, данная процедура может оказаться очень затратной. В данном случае стимулированием решения спора во внесудебном порядке будет введение в законодательство возможности возврата процента от суммы государственной пошлины за подачу искового заявления в зависимости от стадии, на которой стороны изъявили желание урегулировать спор с помощью медиации или покрытия затрат на проведение медиации в размере $30-50 \%$ из суммы уплаченной стороной при подаче иска.

Еще одна проблема исходит непосредственно от граждан и заключается в недоверии к альтернативным процедурам урегулирования споров, поскольку такие организации являются частными, а следовательно неблагонадежными. Такая позиция достаточно четко заметна при ознакомлении со справкой «О практике применения судами Федерального закона» от 27 июля 2010 г. № 193- Ф3 «Об альтернативной процедуре урегулирования споров с участием посредника (процедуре медиации) за 2015 год» [8]. Так, за 2015 г. было рассмотрено 15819942 дел, из которых в 1115 случаях спор был решен путем проведения медиации $(0,007 \%$ от всех рассмотренных дел). Стоит отметить, что годом ранее количество дел, урегулированных с помощью медиации составило 1329 (0,01 \% от рассмот- ренных). Глядя на такую статистику, можно сделать вывод, что институт медиации не только не развивается, но и теряет свою востребованность. Однако необходимо подчеркнуть, что решение этой проблемы может быть только в том случае, если граждане будут больше осведомлены о самой процедуре, совершенствование правовой культуры, правосознания граждан с помощью активной просветительской работы самих медиаторов, органов местного самоуправления, средств массовой информации и государственных органов поможет настроить людей на активное использование медиации как досудебного урегулирования конфликта или спора.

Отсутствие централизации системы альтернативной процедуры разрешения споров в научной литературе также относят к одной из причин низкой популярности медиации среди населения [3]. Возможно, создание городских, областных, окружных и федеральных союзов медиаторов. Использование психологических методов и приемов, которые позволят сделать процедуру медиации максимально эффективной [7]. Предоставление полномочий суду направлять участников правового спора к профессиональному медиатору [4].

Такой подход позволил бы эффективнее реагировать на регулярные изменения в общественных отношениях и совершенствовать профессиональный уровень предоставления услуг посредничества. А также государство выигрывало бы в том, что позволило бы разгрузить финансируемые им суды и сосредоточить усилия судей на сложных спорных делах [9].

\section{Выводы}

В завершение следует учитывать, что процедура медиации в Российской Федерации существует довольно длительное время, она нашла свое отражение в законодательстве, которое, как было выяснено ранее, несовершенно и содержит некоторое количество недоработок. Также существуют иные проблемы для повсеместного применения посредничества как альтернативы судебному порядку разрешения споров, и чтобы их преодолеть, вероятнее всего, должна произойти активизация сообщества профессиональных медиато- 
ров по популяризации своей деятельности. Несмотря на все существующие затруднения и барьеры в применении альтернативной процедуры решения споров, данная область остается интересной для исследования научными деятелями и в настоящий момент уже существует большое количество научных работ, однако законодатель едва заметно предпринимает активные действия по устранению спорных вопросов и совершенствованию законодательства, связанные с данным институтом.

\section{СПИСОК ЛИТЕРАТУРЫ}

1. Аллахвердова, О. В. История развития медиации / О. В. Аллахвердова, Е. Н. Иванова // Вестник Санкт- Петербургского университета. Серия 6. 2007. - Ч. 2, вып. 2. - С. 74.

2. Гражданский процессуальный кодекс Российской Федерации от 14.11.2002 № 138-ФЗ (ред. от 08.12.2020) // СПС КонсультантПлюс. - Электрон. текстовые дан. - Режим доступа: http://www.consultant.ru /document/cons_doc_LAW_39570 (дата доступа 13.12.2020). - Загл. с экрана.

3. Исаенкова, О.В.Цивилистический процесс в России - основные тенденции / О. В. Исаенкова // Вестник ТГУ. - 2016. - № 1. - С. 5-10.

4. Калашникова, С. И. Медиация в сфере гражданской юрисдикции / С. И. Калашникова. - М. : Инфороник-Медиа, 2011.- С. 304.

5. Кодекс административного судопроизводства Российской Федерации от 08.03.2015 № 21-ФЗ (ред. от 08.12.2020) // СПС КонсультантПлюс. -Электрон. текстовые дан. - Режим доступа: http:// www.consultant.ru/document/cons_doc_LAW_176147 (дата обращения: 13.12.2020). - Загл. с экрана.

6. Ресурсный центр медиации: Стоимость процедуры медиации в АНО «Уральский центр медиации» // Ресурсный центр медиации. - Электрон. текстовые дан. - Режим доступа: http:// mediators.ru/rus/regional_mediation/ural/docs2/text2 (дата обращения: 16.11.2016). - Загл. с экрана.

7. Романова, Н. М. Проблемы теории и практики медиации: психологический анализ / Н. М. Романова // Перспективы становления и развития медиации в регионах : сб. материалов I Всерос. науч.практ. конф. с международным участием (4 декабря 2015 г.). - Саратов : Издательский центр «Наука», 2016. - C. 97-103.

8. Справка о практике применения судами Федерального закона от 27 июля 2010 г. № 193-Ф3 «Об альтернативной процедуре урегулирования споров с участием посредника (процедуре медиа- ции)» за 2015 год, утвержденная Президиумом Верховного Суда РФ 22 июня 2016 года // СПС КонсультантПлюс. - Электрон. текстовые дан. - Режим доступа: http://www.consultant.ru/document/cons doc_LAW_200160. - Загл. с экрана.

9. Судоргина, Е. В. Медиация в гражданском и арбитражном процессе / Е. В. Судоргина // Вопросы российского и международного права. - 2018. T. 8, № 10A.-C. 40-46.

10. Федеральный закон «Об альтернативной процедуре урегулирования споров с участием посредника (процедуре медиации)» от 27.07.2010 № 193-Ф3 (последняя редакция) // СПС КонсультантПлюс. - Электрон. текстовые дан. - Режим доступа: http://www.consultant.ru/document/cons doc LAW 103038 (дата обращения: 13.12.2020). Загл. с экрана.

\section{REFERENCES}

1. Allakhverdova O.V., Ivanova E.N. Istoriia razvitiia mediatsii [History of the Development of Mediation]. Vestnik Sankt-Peterburgskogo universiteta. Series 6, 2007, pt. 2, no. 2, pp.73-77.

2. Grazhdanskij processual'nyj kodeks Rossijskoj Federacii ot 14.11.2002 g. № 138-FZ [Civil Procedure Code of the Russian Federation of November 14, 2002 No. 138-FL]. SPS "Konsul 'tantPljus". URL: http:// www.consultant.ru/document/cons_doc_LAW_39570.

3. Isaenkova O.V. Civilisticheskij process $\mathrm{v}$ Rossii - osnovnye tendencii [Civilistic Process in Russia - Main Trends]. Tambov University Bulletin, 2016, no. 1, pp. 5-10.

4. Kalashnikova S.I. Mediacija v sfere grazhdanskoj jurisdikcii [Mediation in the Field of Civil Jurisdiction]. Moscow, Inforonik - Media, 2011, pp. 304.

5. Kodeks administrativnogo sudoproizvodstva Rossijskoj Federacii ot 08.03.2015 g. № 21-FZ [Code of Administrative Procedure of the Russian Federation of March 08, 2015 No. 21-FL]. SPS "Konsul tantPljus". URL: http://www.consultant.ru/document/cons doc_LAW_176147.

6. Resursnyj centr mediacii: Stoimost' procedury mediacii v ANO «Ural'skij centr mediacii» [The Cost of the Mediation Procedure in the ANO "Ural Mediation Center"]. Resursnyj centr mediacii [Resursnyj centr mediacii]. URL: http://mediators.ru/ rus/regional_mediation/ural/docs2/text2.

7. Romanova N.M. Problemy teorii i praktiki mediacii: psihologicheskij analiz [Problems of the Theory and Practice of Mediation: Psychological Analysis]. Perspektivy stanovlenija i razvitija mediacii $v$ regionah: Sb. materialov I Vserossijskoj nauchnoprakticheskoj konferencii s mezhdunarodnym 
uchastiem (4 dekabrja 2015 g.) [Prospects for the Formation and Development of Mediation in the Regions: Sat. Materials of the I All-Russian Scientific and Practical Conference with International Participation (December 4, 2015)]. Saratov, Publishing Center "Science", 2016, pp. 97-103.

8. Spravka o praktike primenenija sudami Federal'nogo zakona ot 27 ijulja 2010 g. № 193-FZ «Ob al'ternativnoj procedure uregulirovanija sporov $\mathrm{s}$ uchastiem posrednika (procedure mediacii)» za 2015 god, utverzhdennaja Prezidiumom Verhovnogo Suda RF 22 ijunja 2016 goda [Certificate on the Practice of Application by Courts of the Federal Law of July 27, 2010 No. 193-FZ "On an Alternative Procedure for Resolving Disputes with the Participation of a Mediator (Mediation Procedure)" for 2015, Approved by the Presidium of the Supreme Court of the Russian Federation on June 22, 2016]. SPS "Konsul tantPljus". URL: http://www.consultant.ru/document/cons doc_LAW_200160.

9. Sudorgina E.V. Mediacija v grazhdanskom i arbitrazhnom processe [Mediation in Civil and Arbitration Proceedings]. Voprosy rossijskogo i mezhdunarodnogo prava, 2018,vol. 8, no. 10A, pp. 40-46.

10. Federalnyi zakon «Ob alternativnoi protsedure uregulirovaniia sporov s uchastiem posrednika (protseduremediatsii)» ot 27.07.2010 g. № 193-FZ[Federal Law "On an Alternative Procedure for Resolving Disputes with the Participation of a Mediator (Mediation Procedure)" of July 27, 2010 No. 193-FL]. SPS "Konsul 'tantPljus". URL: http://www.consultant.ru/ document/cons_doc_LAW_103038.

\section{Information About the Author}

Olga A. Derbisheva, Senior Lecturer, Department of Civil Law and Procedure, Donetsk Academy of Internal Affairs of the Ministry of Internal Affairs of the Donetsk People's Republic, Prosp. Bogdana Khmelnitskogo, 84, 83000 Donetsk, Donetsk People's Republic, olga.aleksandrovna.d@mail.ru, https://orcid.org/0000-0002-8483-2263

\section{Информация об авторе}

Ольга Александровна Дербишева, старший преподаватель кафедры гражданского права и процесса, Донецкая академия внутренних дел Министерства внутренних дел Донецкой Народной Республики, просп. Богдана Хмельницкого, 84, 83000 г. Донецк, Донецкая Народная Республика, olga.aleksandrovna.d@mail.ru, https://orcid.org/0000-0002-8483-2263 